\title{
VIEWPOINTS
}

\section{Mottainai Ethics and the Sustainability of Our World}

\author{
Yasushi Suzuki*
}

The International Seminar on Islam and Green Technology, held on 16 November 2016 at IAIS Malaysia, suggested that a considerable gap exists between the ideals of Islamic teachings on environmental protection and the realities of the practices of Muslim individuals and communities. Many speakers therefore proposed that we should 'change' our consumption and production behaviours in accordance with the normative teachings of the Qur'an and hadith, which emphasise mankind's accountability and responsibility towards maintaining balance and harmony in what Allah the Almighty has created. Here I would like to introduce the Japanese ethical concept of 'mottainai' in the hope that it can contribute to further discussions on the sustainability of our world.

Mottainai (もつたいない勿体無い) is a Japanese term meaning "a sense of regret concerning waste when the intrinsic value of an object or resource is not properly utilised." The expression "Mottainai!" can therefore be uttered as an exclamation when something useful, such as food or time, is wasted, meaning roughly "Oh, what a waste!" In addition to its primary sense of 'wasteful', the word is also used to mean "impious; irreverent" or "more than one deserves."

It is suggestive that this word has these two different meanings: "what a waste!" and "more than one deserves." This demonstrates an important dimension of the traditional Japanese ethical approach to consumption. On the one hand, before a person buys an object (when the goods have not yet been owned by them), they should check with modesty whether they deserve the goods. If they find (or they think that they should find) another inexpensive item which they would better deserve, they think of the first goods as "mottainai!" meaning "more than one deserves!" On the other hand, after they have bought an object (when the goods have already been owned by them), they check with modesty whether they still deserve the goods. If they throw away the goods which they think they still deserve, they think of that action of throwing away as "mottainai!" meaning "what a waste!" An anonymous writer from a well-known online encyclopedia says that "Mottainai in Japanese refers to far more than just physical waste 
(resources). It can refer to wasted and wasteful efforts and actions, activities, time, souls, talents, emotion, minds, dreams, and potential. It is even used to refer to thought patterns that give rise to wasteful action." If a person does not make an effort to fully utilise his/her capacity or ability, the underutilised capacity or ability (and their behaviours) would be construed as mottainai.

In parallel, we should note the recent trend encouraging Japanese people to quantify the objective (or at least objectifiable) value of goods and services so that they do not pay more than the value of what they consume - the so-called 'financialisation' named by Ronald Dore, a famous Japanologist. This trend, however, has unwisely changed the criteria for mottainai in Japan. Now, when individuals do not feel that the real value of goods is equal to the offered 'price', they have come to use mottainai to mean "this is too expensive!" Here we should note that they seem to have replaced themselves with the market price as the criteria for judging whether each consumption can be construed as mottainai. In other words, though they used to be 'spiritual seekers' who bought modest goods and trained themselves (kokki) to deserve those goods, they are now mere 'utility maximisers', or homo-economicus, who only consider the market price in accordance with the tread of financialisation.

In spite of the abovementioned trend, in my view the word mottainai still demonstrates the traditional Japanese ethical approach to pre-consumption and post-consumption. Concerning pre-consumption, it demonstrates that the Japanese were disciplined to buy modest goods, as though they were not yet worthy of luxurious goods, thereby respecting the virtue of thrift. Concerning post-consumption, the concept demonstrates how the Japanese were disciplined to use their already-owned goods for as long as they could, as if by doing so they would become worthy of the owned goods, again respecting the virtue of thrift. This ethical outlook on consumption was underpinned by the virtue of modesty and self-realisation. It is said that in ancient Japanese, mottainai had various meanings, including a sense of gratitude mixed with 'shame' for receiving a greater favour from a superior than was properly merited by one's station in life. In that context, mottainai is a compound word, mottai plus nai. Mottai refers to the intrinsic dignity or sacredness of a material entity, while nai indicates an absence or lack. The term mottainai was also traditionally used by Buddhists to indicate regret at the waste or misuse of something sacred or highly respected, such as religious objects or teachings.

It is worth noting that there are words with similar connotations to mottainai in other Asian languages: 'mubazir' or 'eman-eman' in Javanese/Indonesian; 'opocoi' in Bengali; 'aeytadal' in Urdu; 'mitbyayita' in Hindi; and 'mobazir' in Arabic. In most societies, therefore, we see a similar ethos encouraging economic agents to respect the virtue of thrift (referring to something that, if not 
fully utilised, will be a waste), the virtue of accepting the present as enough (not exceeding their own bounds), the virtue of moderation and the virtue of sharing goods among other society members.

Mottainai ethics was originally based on an individual's modesty and subjective ideals respecting the virtues of thrift, moderation and self-realisation. The late Wangari Maathai (1940-2011), a Kenyan environmentalist and the 2004 Nobel Peace Prize winner, who founded the Green Belt Movement and worked as an environmentalist and civil society activist, became a well-known promoter of mottainai as a tool for environmental protection. When she visited Japan for an event related to the Kyoto Protocol in 2005, she was given a shirt with the word 'MOTTAINAI' written on it. She wore that shirt at the Kyoto Protocol conferences and asked the audience to use the word in their everyday lives. For this, she became a widely-recognised celebrity in Japan. Her subsequent 'MOTTAINAI' Campaign aimed to shape a sustainable and cyclical society on a global scale by promoting the most efficient use possible of limited resources, as represented by the '3Rs': to 'reduce' waste, 'reuse' finite resources, and 'recycle' what we can. She deeply respected the Japanese word mottainai and sought to spread it around the world as a common keyword for conserving the environment. It is time that we recall our own ancient wisdom for the sustainability of our world.

* Yasushi Suzuki is Professor at the Graduate School of International Management, Ritsumeikan Asia Pacific University, Japan. His email is szkya@apu.ac.jp 